Differential Reinforcement of Low Rates: A Systematic Review

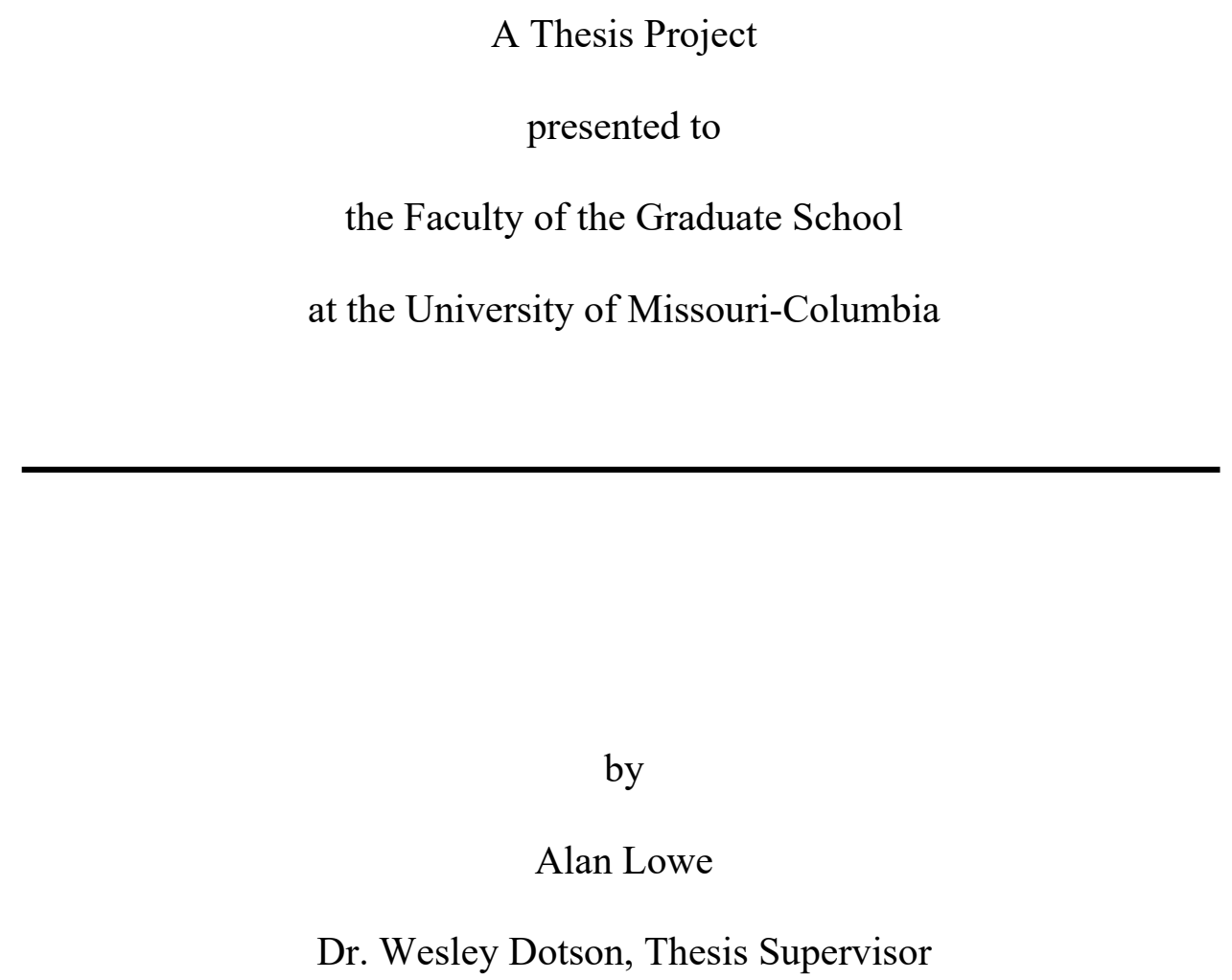

MAY 2021 
DIFFERENTIAL REINFORCEMENT OF LOW RATES

The undersigned, approved by the dean of the Graduate School, have examined the thesis entitled

DIFFERENTIAL REINFORCEMENT OF LOW RATES: A SYSTEMATIC REVIEW

presented by Alan Lowe, a candidate for the degree of Master of Science, and hereby certify that, in their opinion, it is worthy of acceptance.

Dr. Wesley Dotson

Dr. Jennifer Weyman

Dr. Lea Ann Lowery 
Running head: DIFFERENTIAL REINFORCEMENT OF LOW RATES

\section{ACKNOWLEDGEMENTS}

First and foremost, I am extremely grateful to my thesis committee, Dr. Wesley Dotson, Dr. Jennifer Weyman, and Dr. Lea Ann Lowery for their invaluable advice, continuous support and patience during my thesis project. I would also like to thank Kyle Hamilton for his technical support, and his initial guidance in the literature review, and for taking data. Finally, I would like to express my gratitude to all my colleagues for a cherished time spent together in the clinic, and in social settings. I would especially like to thank my wife. Without her tremendous understanding and encouragement these past two years, it would be impossible for me to complete my study. 


\section{TABLE OF CONTENTS}

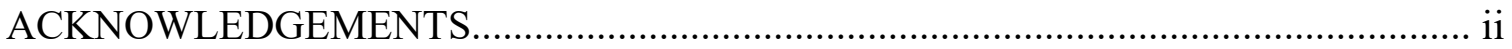

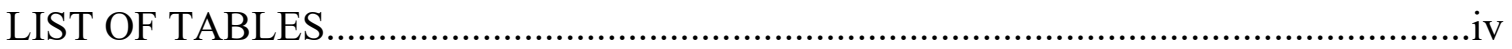

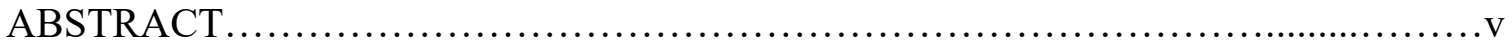

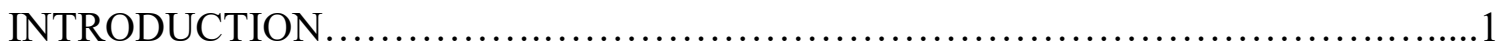

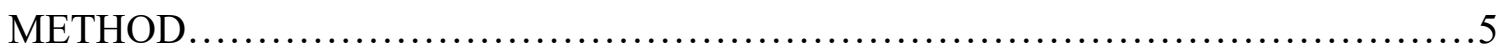

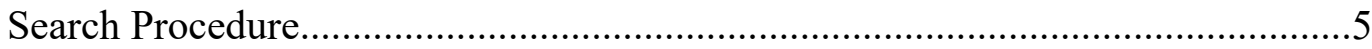

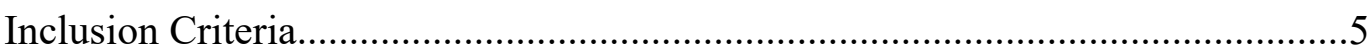

Inter-observer Agreement (IOA) .....................................................................6

Structure

RESULTS

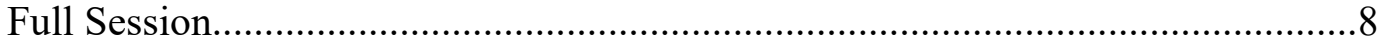

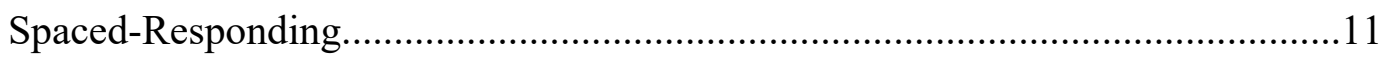

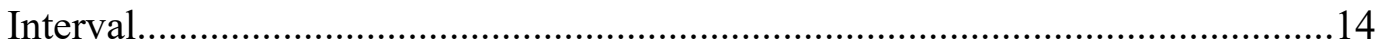

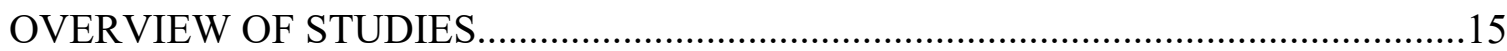

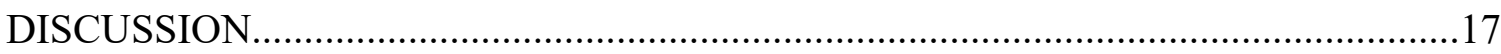

Percentage of Improvements / Limitations......................................17

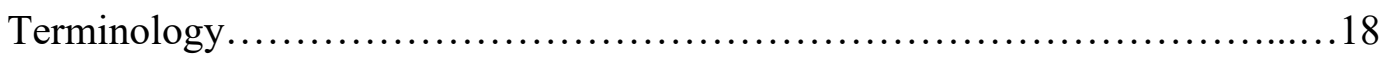

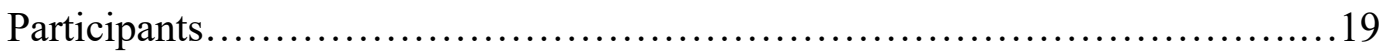

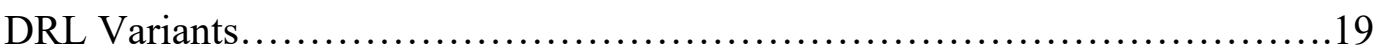

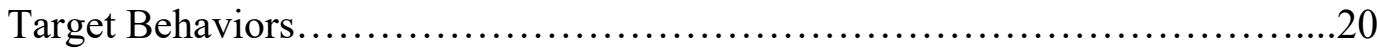

Functional Analysis........................................................20

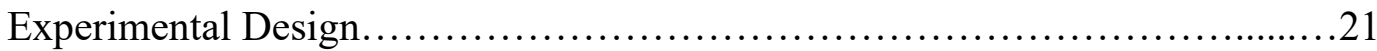




\section{DIFFERENTIAL REINFORCEMENT OF LOW RATES}

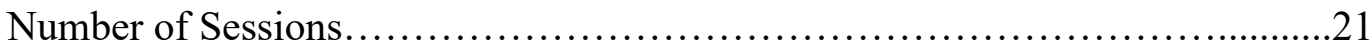

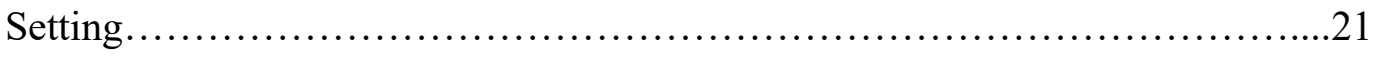

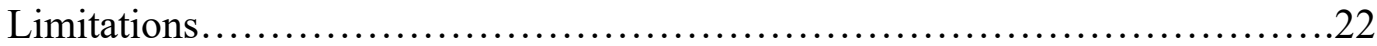

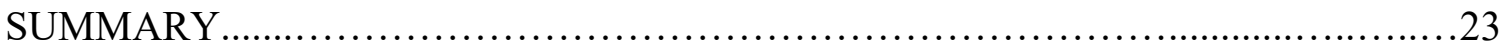

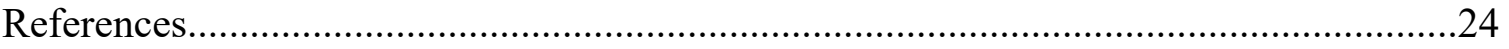

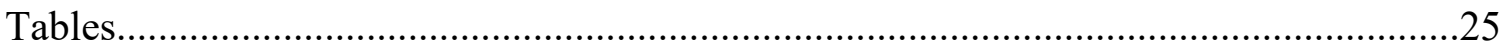

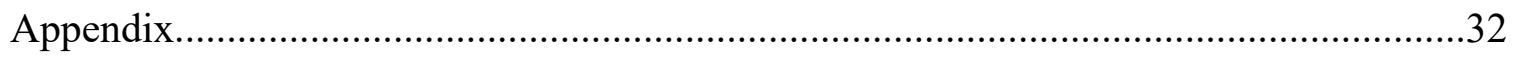


DIFFERENTIAL REINFORCEMENT OF LOW RATES

\section{LIST OF TABLES}

Table 1. Table depicting the summary of Differential Reinforcement of Low Rate

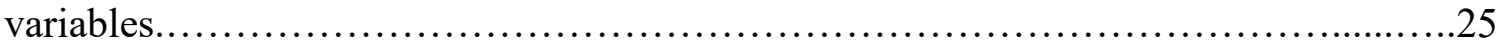

\section{APPENDIX}

Appendix A. Data base search sheet for database used, keywords, number of hits, citations, and eligibility check .......................................................

Appendix B. Code sheet for academic database, citation, report of characteristics, and

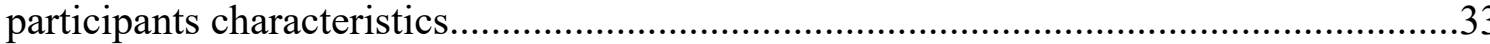




\title{
DIFFERENTIAL REINFORCEMENT OF LOW RATES
}

\begin{abstract}
Differential reinforcement of low rates (DRL) is a differential reinforcement variation used to reduce response rates of but not extinguish, a behavior. This review summarizes the applied literature on DRL variations used with children. Reviewed studies included DRL procedures that targeted on challenging behavior. Experimenters identified 21 studies through a systematic search process and evaluated several characteristics of each study including children treated, participants, DRL variations, target behaviors, functional analysis, design, number of sessions, settings, and percentage of improvement. Discussion includes prominent findings, implication and recommendations for future.
\end{abstract}

Keywords: differential reinforcement of low rates, full-session, spacedresponding, interval, autism spectrum disorder, intellectual disability 


\section{DIFFERENTIAL REINFORCEMENT OF LOW RATES}

\section{Introduction}

Individuals diagnosed with Autism Spectrum Disorder (ASD) exhibit a range of behavioral characteristics (American Psychiatric Association, 2013). Among those are restricted and repetitive behaviors, defined as complex behavior with circumscribed interest, rigid and invariant routines, arranging and ordering, repetitive motions, and repetitive manipulations of objects (Turner, 1999). Different topographies of restricted and repetitive behavior include playing in a particular pattern, lining things up in patterns or rows, hand flapping, and object spinning.

Restricted and repetitive behavior in children with developmental disabilities often interfere with academic skill acquisition. Koegel and Covert (1972) demonstrated that RRBs interfere with academic skill acquisition. The experimenters evaluated the acquisition of discriminative behavior between three autistic children with high rates of self-stimulatory behavior when engaging in self-stim and when not not engaging in selfstim. The experimenters found that: (a) the participants could not discriminate while engaged in a self-stimulatory behavior; (b) reduction of self-stimulatory behavior allowed the participants to engage in accurate responding; (c) the participant's discrimination learning with the suppression condition corresponded with a reduction of self-stimulatory behavior. and may evoke challenging behavior when interrupted.

Previous research has also shown that interrupting restricted and repetitive behavior may evoke challenging behavior. For example, Leon et al. (2013) assessed the consequences of manipulating parts on a game board to see if problem behavior occurred. When experimenters manipulated the game board pieces outside of their initial location, the participant would engage in problem behavior to fix the stimuli. 


\section{DIFFERENTIAL REINFORCEMENT OF LOW RATES}

Due to age-inappropriate forms of behavior, their influence with interactions between peers and adults, restrictive and repetitive behavior have been labeled as socially stigmatizing (Cunningham \& Schreibman, 2008; Koegel \& Covert, 1972; Lovaas et al., 1971). Currently, behavioral interventions are the most practical methods to diminish problem behavior associated with RRB in individuals with Autism Spectrum Disorder (National Autism Center, 2009). A third issue related to restricted and repetitive behavior is that it can be socially stigmatizing (Cunningham \& Schreibman, 2008). Cunningham and Schreibman (2008) suggest that stereotypy is perceived as inappropriate because of duration, form, and intensity, and that it is uncomfortable for guardians who bring their children to public places. Because of this stigma, the children may engage in peer and adult interactions less, which has direct undesirable consequences for their development. In summary, they continued treatment for RRB is to be warranted.

Practitioners can choose from a wide range of procedures for decreasing or eliminating problem behaviors (e.g., extinction, reinforcement, and punishment). Although interventions based primarily on extinction or punishment are often effective, unwanted side effects may occur. Emotional and high rates of challenging behavior when behavior with a long history of reinforcement no longer reinforced. Punishment has often evoked escape, avoidance, and aggression (Poling \& Ryan,1982). It also must be noted that you sometimes don't want to eliminate a target behavior as well. For example, Austin and Bevan (2011) evaluated a differential reinforcement procedure to reduce excessive children request for attention. In a classroom, it is appropriate for a student to request attention, however, we can reduce these behaviors if they are excessive. This allows the teacher to engage with other classmates. 


\section{DIFFERENTIAL REINFORCEMENT OF LOW RATES}

Behavior analysts use differential reinforcement to diminish or eliminate problem behaviors to avoid these unwanted side effects and move away from interventions that incorporate punishment and extinction (Cooper et al., 2020). They also use DRL procedures when eliminating a target behavior entirely is not the goal. There are three different differential reinforcement procedures. The first type of differential reinforcement is a differential reinforcement of other behaviors (DRO). DRO is a behavioral, reinforcement-based procedure comprising the delivery of a consequence contingent on the absence of challenging behavior (Wong et al., 2014). For example, Allen et al. (1982) applied a DRO procedure to decrease third-grade students' disruptive classroom behaviors. The teachers set a timer to 5 minutes that continued to run as long as no disruptive behavior occurred. The experimenter reset the timer, and a new 5 min interval began if any student engaged in disruptive behavior during the interval. If the student did not engage in any disruptive behaviors during that 5 minutes, then they were provided reinforcement. The results demonstrated that the DRO procedure was effective in decreasing disruptive behavior in the classroom setting.

The next type of differential reinforcement procedure is differential reinforcement of alternative behavior (DRA), which denies the reinforcer for undesired behavior while concurrently reinforcing an alternative behavior (Roane et al., 1999). For example, LeGray et al. (2013) applied a DRA procedure to decrease disruptive behavior while simultaneously increasing children's appropriate behavior in center-based classrooms. The child earned the reinforcer for appropriate vocalizations, and inappropriate vocalizations were extinguished. 


\section{DIFFERENTIAL REINFORCEMENT OF LOW RATES}

The last type of differential reinforcement procedure, designed to decrease but not eliminate challenging behavior, is differential reinforcement of low rates (DRL). Reinforcement contingencies, based on delivering reinforcement only when a target behavior does not exceed a predetermined amount in a set period (Ferster \& Skinner, 1957). Deitz (1977) proposed three methods for programming DRL contingencies. The first proposed variant of DRL is the full-session DRL, which includes delivering a reinforcer if a behavior occurs fewer than a fixed number of times in a complete session. For example, Handen et al. (1984) evaluated a full-session DRL to reduce repetitive speech in a boy diagnosed with ASD using a changing criterion design. They gave the participant an allocated number of times he could engage in repetitive speech at each criteria level, and delivered reinforcement at the end of each day, if he had fewer than that amount. The procedure was effective in reducing repetitive speech to a final rate lower than baseline.

The second proposed DRL variant is interval DRL. A session is broken up into equal intervals, and reinforcement is provided when falls below the predetermined criterion for each interval (Deitz,1977). For example, Looney et al. (2018) used an interval DRL and self-monitoring to reduce repetitive body movements in children with Autism. During the interval DRL, they provided the child with a rule "If you have less than ten body movements, you can have chocolate"). Following this rule, the therapist would start a timer, and contingent on making less than ten body movements, the child would receive chocolate at the end of the interval.

The last proposed DRL variant is the spaced responding DRL. During the spaced responding DLR, reinforcement is provided for each response that is separated from the 
DIFFERENTIAL REINFORCEMENT OF LOW RATES

previous response by a minimum amount of time (Deitz,1977). For example, Lennox et al. (1987) used a spaced-responding DRL reduce the rate of an eating response for children diagnosed with an intellectual disability. They implemented a 15-s spacedresponding interval, in which the child could only take a bite if it has been at least 15 seconds since the last bite ended.

The purpose of this systematic review is to examine previous studies utilizing DRL as an intervention method with children, identify trends and limitations in that literature, and make recommendations for future research.

\section{Methods}

\section{Search Procedure}

To identify relevant literature DRL procedures, researchers conducted a systematic literature review. First academic electronic databases: EBSCO host, PsychINFO, PubMed, and SpringerLink were searched. The search term combinations included: (a) "differential reinforcement of low rates" and "autis*", (b) "differential reinforcement of low rates and intellectual disabilities", (c) "interresponse time" and "autis*", (d) "interresponse time" and "intellectual disabilities".

\section{Inclusion Criteria}

The following criteria were used to identify studies that would be included in the literature review. Each paper had to: (a) be published in a peer-reviewed journal between 1957 and 2020; (b) incorporate a DRL variant to reduce a target behavior; (c) include a minimum of 16 sessions using the DRL variant; (d) use a single-subject design; (e) include a minimum of one human participant. We based the minimum of 16 sessions on previous research that has demonstrated there needs to be 16 sessions for treatments to 
DIFFERENTIAL REINFORCEMENT OF LOW RATES

work (Flückiger et al., 2020). Following this, we reviewed the reference sections of each article located during the keyword search. Studies that were not written in English, or not peer-reviewed, and used nonhuman subjects were excluded from this review. The articles included in this review are summarized in Table 1.

\section{Inter-observer Agreement (IOA)}

A coding sheet (Appendix A) we used to summarize each DRL study that met the inclusion criteria shown above. We did not include articles that did not meet eligibility criteria in this review. The coding sheet assessed (a) report characteristics, (b) participant characteristics, and (c) eligibility checklist. The primary author coded each of the articles included in this review. Two additional researchers were trained to independently code using the provided data sheets in Appendix A, and Appendix B. 100\% of the included articles were reviewed by the last two researchers. A second researcher independently used the provider's search procedures and inclusion criteria as described above. The two reader's evaluations were compared, and we discussed the number of the agreements and disagreements. For each of the following articles that were not agreed on by each reader, we discussed the articles thoroughly and them thoroughly an agreement was made to include them for the literature review for $100 \%$ of the time.

\section{Structure}

The rest of the paper include three sections (a) description of articles, (b) summary of results and (c) discussion. The results section presents a summary of the studies identified in the search organized, as according to which DRL variant was used

(1) full-session, (2) spaced-responding, and (3) interval. Following the brief review of DRL variants, the following variables are summarized across all studies: (a) children 


\section{DIFFERENTIAL REINFORCEMENT OF LOW RATES}

treated (b) number of participants, (c) DRL variations, (d) target behaviors, (e) functional analysis, (f) design, (g) number of sessions, (h) settings, and (i) percentage of improvement. Target behaviors were categorized as prosocial behaviors, RRBs, and arbitrary responses (Computer programs). Prosocial behaviors for our study includes any behaviors that is not categorized under RRBs or an arbitrary response. RRBs include repetitive behaviors, motor and vocal stereotypy, and question asking. Arbitrary responses include any behavior that is simulated from a computer program. Percentage of improvement was calculated by subtracting the final mean value in treatment from the mean value in baseline and taking that number and divide that amount by the absolute value of the baseline mean value. Next, we multiplied that number by 100 to get percentage improvement (e.g., (Starting Value - Final Value) / |Starting Value|] x 100).

\section{Results}

The results are depicted in Figure 1, with the initial search yielding 40 different articles. Authors and researchers screened the title and abstract and removed duplicate articles to initially identify 16 relevant articles. A forward search of the 16 articles identified 5 additional articles for 21 articles.

Once we identified the studies, we reviewed full-session, spaced-responding, and interval DRL variants. First, discussed the most utilized DRL variant full-session, following by spaced-responding, and finally we analyzed the interval DRL, We provide a brief summary for all 21 articles including all relevant variables (e.g., percentage of improvement, setting, design, type of DRL variant, participants diagnosis). 
DIFFERENTIAL REINFORCEMENT OF LOW RATES

\section{Full Session}

14 articles met criteria for using a full-session DRL. For example, Turner et al. (1990) evaluated a full-session DRL to measure the impact on verbal aggressions of a 21year-old man using a multiple-baseline design in a therapy room setting. During the fullsession DRL, the participant was provided with a contingency that if they engaged in more than five verbal aggressions, they would not receive reinforcement. The visual analysis showed there was an improvement in the reduction of challenging behavior.

Kostinas and colleagues (2001) evaluated a full-session DRL to reduce perseverative verbalizations with an adult diagnosed with intellectual disability using a reversal in a therapy room setting. During the full session, the participate could engage in 12 verbalizations or less in a session to receive reinforcement. If the participant exceeded 12 verbalizations, he was not provided reinforcement. The experimenters used a reversal design, and the results indicated $100 \%$ improvement in the reduction perseverative verbalizations.

Austin and Bevan (2011) evaluated the effects of a full-session DRL to diminish the total of requests for attention with three classroom participants diagnosed with ASD. During the full-session DRL, they provided each student with an index card with boxes that correlated to the amount of times they could engage in the target behavior. The student could engage in requesting attention up to 10 times, the number of boxes they had. The full-session DRL led to reduced repetitive demands for attention in this classroom setting by $96 \%$.

Otalvara et al. (2020) replicated the effects of Austin and Bevin (2011) by evaluating the effect of full-session DRL on the response rate of repetitive question 


\section{DIFFERENTIAL REINFORCEMENT OF LOW RATES}

asking with adults diagnosed with an intellectual disability. They also wanted to determine whether this reduction would increase task engagement. During Baseline, instructors answered each question asked by the participants. During the full-session DRL, they provided each student an index card with the allocated number of boxes they could engage in question asking, and if they had a minimum of one box remaining unsigned, that participant received one-on-one attention with a staff member. The experimenters found that a full-session DRL is successful in a work setting to decrease question asking, and that notecards helped signal a low number of requests for attention. A limitation to this study was that the subjects fell into a "ceiling effect" as the task engagement was already high, and it made it less likely that the experimenters would detect an percentage increase in work productivity.

Bonner and Borrero (2017) evaluated full-session DRL contingency on the impact on severe problem behavior (SIB) in a therapy room setting using a reversal design with four participants diagnosed with ASD. During the full-session DRL if the participant met the contingency of not engaging in severe problem behavior for the allocated predetermined tolerance criterion, then they would receive reinforcement. The results show a $97 \%$ improvement in the reduction of severe problem behavior.

Deitz and Repp (1973) evaluated a later named full-session DRL on the reduction of classroom behavior with one participant diagnosed with intellectual disabilities using a reversal design in a classroom setting. During the full-session DRL, if the participant made three or fewer "talk-outs," he would receive 5 min of reinforcement.

Laprime and Dittrich (2014) evaluated a full-session DRL using a changing criterion design on vocal stereotypy with a participant diagnosed with an autism spectrum 


\section{DIFFERENTIAL REINFORCEMENT OF LOW RATES}

disorder. treatment package with response cost on vocal stereotypy with a participant diagnosed with an autism spectrum disorder. The results demonstrated that the fullsession DRL, along with the treatment package comprising discrimination training and differential reinforcement with response cost, effectively reduced stereotypic behavior by $83 \%$

Gadaire et al. (2017) evaluated a full-session DRL with five participants diagnosed with intellectual disabilities using a reversal, while in a playground setting. During the full-session DRL, participants would earn stickers that could be exchanged if they engaged in two or fewer positive comments. The results show an improvement relative to baseline.

Handen et al. (1984) evaluated a full-session DRL to reduce repetitive speech in a boy diagnosed with ASD using a changing criterion design. They gave the participant an allocated number of times he could engage in repetitive speech at each criteria level, and delivered reinforcement at the end of each day, if he had fewer than that amount. The procedure was effective in reducing repetitive speech to a final rate lower than baseline.

Shaw and Simms (2009) evaluated a full-session DRL using a changing criterion design with three participants diagnosed with an intellectual disability. The study was conducted in a classroom setting. During the full-session DRL, they provided each with trade-in rewards and reinforcers based on meeting the DRL contingency. The results demonstrated that the full-session DRL was successful in decreasing the frequency of targeted behaviors by $86 \%$.

Becraft et al. (2017) evaluated a full-session and spaced-responding DRL variant and measure the impact on excessive bids for teacher's attention in a classroom setting 


\section{DIFFERENTIAL REINFORCEMENT OF LOW RATES}

using a multi-element design. There were three typically developing participants. The results showed an improvement of $61 \%$ using full-session, and $66 \%$ improvement in the reduction of bids for attention.

14 out of the 21 articles incorporated a full-session DRL variation. 6 of the 14 (43\%) articles included participants with a diagnosis of intellectual disability. The average number of participants that took part in these studies was 4 . The most common challenging behaviors targeted for reduction were pro-social behaviors such as question asking, which was the targeted behavior for six out of the fourteen (43\%) articles. 11 out of the $14(79 \%)$ articles did not include a functional analysis and were evaluated using a reversal design. The average number of sessions for this variation was 69 sessions. 8 of the $14(57 \%)$ studies took place in the classroom setting. Across all full-session articles, full-session yielded an improvement in the reduction of a variety of challenging behaviors by $82 \%$.

\section{Spaced-Responding}

Singh et al. (1981) evaluated spaced responding DRL to reduce stereotypical responses in three participants with intellectual disabilities in a therapy room setting. They compared two conditions: baseline and spaced responding DRL using a reversal design. In baseline, they observed and recorded stereotypic responses (complex finger movements, repetitive body movements, rocking, mouthing) for ten days. In Spaced Responding Condition, a 12 second IRT contingency for stereotypic responding was in effect, in which the reinforcement was descriptive praise. There were three phases, 30 s, $60 \mathrm{~s}, 180 \mathrm{~s}$, for five days. Responding DRL condition was reinstated with an IRT of 180

s. The experimenters observed the space responding DRL contingency with an IRT of 12 


\section{DIFFERENTIAL REINFORCEMENT OF LOW RATES}

$\mathrm{s}$ immediately decreased the occurrence of stereotypical responding by $86 \%$ and increased social behavior occurrence compared to Baseline.

Lennox et al. (1987) evaluated the effects of a spaced-responding DRL on reducing rapid eating with three individuals diagnosed with intellectual disabilities. For the DRL contingency, they put a 15-s interval into place. If $15 \mathrm{~s}$ elapsed between one bite of food and another bite of food, the participant could take a bite. However, if the participant tried to engage in the eating response, the response was blocked, and the interval was reset. The overall interresponse time increased by $50 \%$ across all participants using the spaced-responding DRL variant.

Jessel and Borrero (2014) compared a full-session contingency to a spacedresponding contingency on arbitrary responses while using a reversal design in a classroom setting with 16 typically developing participants. Both DRL variations used computer programs and had to engage with specific software for varied interval in a human operant arrangement. The results showed an improvement of $36 \%$ in the spacedresponding condition, and $63 \%$ in the full-session condition.

Becraft et al. (2018) compared a full-session contingency, to a spaced-responding contingency on arbitrary responses while also using a reversal design in a classroom setting with five participants who are typically developing. During both contingencies' computer software was set up, and the participants had to engage with the mouse and keyboard a specific number of times to receive reinforcement in the form of a point in the game. The results showed an improvement relative to baseline.

Angelesea et al. (2008) evaluated the effects of a vibrating pager for increasing the duration of meal consumption in three teenagers with autism who were observed to 
DIFFERENTIAL REINFORCEMENT OF LOW RATES

eat too quickly using a reversal design. They taught only participants to take a bite during a spaced-responding interval. The results showed that the vibrating pager successfully increased mealtime's total duration by $58 \%$, slowing consumption for all three participants.

Lennox et al. (1987) assessed several methods for diminishing the rate of eating responses with clients who have been diagnosed with intellectual disabilities using a multiple baseline across subject's design. A time based 15-s response interruption procedure was implemented, which resulted in little change in eating responses. Following the interruption procedure, a spaced-responding DRL 15-s procedure was implemented and decreased eating responses to target levels. The results demonstrated an improvement of $50 \%$ in the rate of eating responses.

Wright and Vollmer (2002) evaluated a spaced-responding variant and replicated and extended the treatment procedures described by Lennox et al. (1987) to reduce rapid eating in girls with intellectual disabilities who engaged in dangerously high food ingestion rates while using reversal design in a therapy room. The procedure included a spaced-responding DRL, response blocking, and prompts. Results showed that the treatment package was effective in reducing the rate of eating by $72 \%$.

Piper et al. (2019) compared performances of a spaced-responding DRL contingency, and a full-session DRL contingency on arbitrary responses while using a reversal design in a classroom with four participants diagnosed with ASD. The results demonstrated that the spaced-responding variant yielded an increase of $73 \%$ improvement, and full-session yielded a $49 \%$ improvement in the reduction of arbitrary responses. 


\section{DIFFERENTIAL REINFORCEMENT OF LOW RATES}

Overall, the literature search revealed that 8 out of the $21(38 \%)$ articles

incorporated a spaced-responding DRL variation. 3 of the 8 articles included participants diagnosed with intellectual disability, autism or typically developing. The average number of participants that took part in these studies was 5. The most common behaviors targeted were pro-social behaviors, which was the targeted behavior for 4 out of the 8 $(50 \%)$ articles. No articles included a functional analysis, and seven out of the eight (88\%) were evaluated using a reversal design. The average number of sessions was 49 sessions. 5 of the $8(63 \%)$ studies took place in the classroom setting. The spacedresponding variation yielded an improvement of $63 \%$ in the reduction of behaviors.

\section{Interval}

Deitz and Repp (1974) introduced a new DRL variant called an interval DRL schedule. In an interval DRL, the total sessions is divided into smaller intervals and experimenters/therapist will deliver a reinforcer if fewer than a specified number of responses occurred. The investigators used a reversal design in a classroom setting to target out-of-seat behaviors using a criteria of two or fewer responses in an interval. They saw an improvement of $96 \%$ in the reduction of talk-outs.

Looney et al. (2018) evaluated the effects of a self-monitoring system and a DRL on decreasing repetitive body movements in children with autism. A trial-based functional analysis revealed that automatic reinforcement maintained repetitive body movements. The treatment comprised teaching the participant to use a self-monitoring system to monitor repetitive body movements. A stimulus control analysis revealed the self-monitoring system gained stimulus control over the body movements, meaning that they were more likely to occur in the system's absence than in its presence. The self- 


\section{DIFFERENTIAL REINFORCEMENT OF LOW RATES}

monitoring system was implemented with a DRL contingency that included providing chocolate if fewer then 10 body movements occurring during a 1 minute interval, and they evaluated their combined effects using a reversal design, and the results showed that repetitive body movements decreased by $92 \%$ with implementing the treatment.

Deitz et al. (1978) evaluated interval DRL to reduce inappropriate classroom behavior of one male with a developmental disability. They compared two reinforcers using DRL treatments, with one comprising exchanging stars for free time contingent on brief intervals in which fewer than two responses occurred, and the other included minutes of access to a sand table was made contingent on two or fewer responses per interval occurred. The results showed that an interval DRL arrangement reduced inappropriate behavior by $89 \%$ in special classrooms.

3 out of the $21(14 \%)$ articles incorporated an interval DRL variant. All 3 articles had participants with different diagnoses (no autism, Autism, and intellectual disabilities). The most targeted behavior was pro-social behaviors being in 2 of the 3 (66\%) articles. Only 1 article included a functional analysis. 3 articles used a reversal design. The average number of sessions for this variation was 41 sessions. 2 of the 3 articles were conducted in a classroom, and one was conducted in a therapy room. Finally, the interval reduced the behaviors by $92 \%$.

\section{Overview of Studies}

63 people between the ages of 4 and 47 took part in the studies. The diagnoses of these people are different, with 16 of 63 (25\%) participants being diagnosed with autism, 26 of $63(41 \%)$ participants being typically developing, and 21 of $63(33 \%)$ participants being diagnosed with an intellectual disability. The most common DRL variation was the 
DIFFERENTIAL REINFORCEMENT OF LOW RATES

full-session DRL implemented in 14 of the 21 articles. The second most frequently employed variant was the spaced-responding DRL used in 8 of the 21 articles. The last DRL variant used was the interval DRL, used 3 of the 21 collected studies. 4 of 21 studies included more than 1 DRL variant.

They targeted 13 different topography of behaviors throughout the studies. Prosocial behaviors were targeted in 13 of the $21(62 \% \%)$ of the collection of studies, followed by RRBs in 5 of the 21 (24\%) and Arbitrary Responses being included in 3 of the 21 studies $(14 \%)$.

17 out of the 21 studies $(81 \%)$ did not conduct a functional behavior assessment (FBA) or conduct initial components of an FBA (e.g., indirect assessment) before beginning the intervention. 4 out of the $21(19 \%)$ used a functional analysis. Of those who conducted an FBA, 2 of the $4(50 \%)$ of those incorporated the DRL as part of a treatment package that used various procedures (e.g., extinction, punishment) to reduce the target behavior.

16 out of the 21 studies used a reversal design. The changing criterion design was used in 3 of the 21. Multi-element and multiple-baseline designs were used in one article each. The total number of sessions addressed in these studies were 1,292. The average number of sessions per article was 64 . There was an outlier that included weeks and days for their study, and we could not allocate them to one of our categorizations (Handen et al., 1984; Turner et al. 1990).

Treatments occurred in a variety of settings; 11 of the $21(52 \%)$ were conducted in a classroom, 9 of the 21 studies (43\%) used a therapy room, and one occurred outside on a playground $(5 \%)$. 
The three DRL variations yielded varied results in regards to range of percentage of improvement. Most of the collected studies included the Full-Session DRL, resulted in an average of $82 \%$ improvement. Spaced-responding DRL yielded a $63 \%$ improvement. Interval DRL variant yielded a 92\% improvement.

\section{Discussion}

The purpose of this literature review was to evaluate the research on DRLs in applied settings. This review of 21 articles revealed DRL's utility with children and adults with both typically and children and with intellectual disabilities and ASD.

\section{Percentage of Improvement / Limitations}

Overall, all DRL variations reduced all targeted behaviors. We made an interesting discovery while examining the DRL literature. We discovered that the interval DRL yielded a higher percentage of reduction compared to both full-session and spacedresponding. The authors believe this increased percentage is because of the interval DRL only having three articles, relative to the full-session and spaced-responding, used in most articles. It is important that we discuss the percentage of improvement for each DRL variant. The DRL was intentionally designed to reduce but not eliminate a behavior, however the interval and full-session DRL were shown to drop the target behavior down to near zero rates. For most prosocial behaviors, it is socially acceptable to reduce but not eliminate behaviors (e.g., requesting attention, question asking). These prosocial behaviors are relevant behaviors that we don't want to occur at a high rate, however we want them to occur at a relevant acceptable rate. Future research should continue to evaluate prosocial behaviors, and RRBs and analyze whether DRL variants are more effective then using punishment, and extinction in classrooms and applied settings. 


\section{DIFFERENTIAL REINFORCEMENT OF LOW RATES}

However, further analyzing these articles leads to the additional discovery that there have been some inconsistencies with the DRL variation terminology.

\section{Terminology}

The way we speak about behavioral occurrences has been a long priority in behavior analysis (Schlinger et al., 1991). Careful use of the discipline's technical terms is essential for effective scientific communication and more precise conceptual analysis. Since 1977, several DRL procedures, including full-session, interval, and spacedresponding, have been included in graduate and undergraduate behavior analysis coursework. Although the definitions are open for discussion, the terms "session" and "interval" have been used inconsistently in recent studies to explain the three DRL procedures' variants.

Becraft et al. (2018) provides an example of this ambiguous terminology. Their definition of the full-session variation needs further clarification, as they based it on an interval less than or equal to a predetermined criterion, rather than a full experimental session. The procedures are like those used in an interval DRL variation. However, it must be noted that Becraft et al. (2018) discussed that Deitz (1977) defines the interval in a full-session DRL as the entire session duration. Alternatively, he names another DRL variation called an interval DRL. According to Deitz, an interval DRL breaks the session into split intervals. The authors of Becraft et al. (2018) provided their opinion that conceptually one may view the interval and full-session DRL as the same procedure, and for their studies, they label the interval DRL as a full-session DRL. Future research should evaluate under what circumstances is the full-session DRL more utilized then a 
DIFFERENTIAL REINFORCEMENT OF LOW RATES

interval DRL. Future researchers should also analyze the differences between sessions, and intervals and defining what makes a session, and an interval.

\section{Participants}

The number of participants that were targeted in each study was slightly higher than average for single-subject research, ranging from 2 to 16 participants (Kazdin,2021). However, there was one outlier that may have altered our average participant age for our literature search. Jessel and Borrero (2014) included 16 participants from the university, which could have been a limitation due to the students needing to be sufficient at manipulating computer mice and had experience using computers. Future research should continue to use a variety of participants.

\section{DRL Variants}

The collection of studies included all three DRL variants. These variants included full-session, spaced-responding, and interval. Full-session DRL has been used the most frequently since its inception in 1977 as it has been one of the more effective variants. However, this yields for further research for the interval DRL as we discovered the interval has a higher percentage of improvement. Because of the limited research on spaced-responding and interval variation, it warrants further research to evaluate under what settings and targeted behaviors does the interval variation provides socially significant results. For example, the spaced-responding DRL variant and interval variant should be evaluated under what results could be demonstrated by using signals in the reduction of RRBs. 


\section{Target Behaviors}

DRL variations can reduce various target behaviors, including bids for attention, SIB, talk-outs, disruptive behaviors, motor, and vocal stereotypy, rapid eating, question asking, attention-maintained behaviors, and verbal aggression. The full-session DRL can be an effective treatment for reducing, if not eliminating, problem behavior. Full-session DRL yields similar results to differential reinforcement of other behavior (DRO). For example, Jessel and Borrero (2014) suggested that a full-session DRL might eliminate responding entirely, similar to a DRO. This is interesting in regards to DRL as the procedure is not designed to eliminate behaviors, but only to reduce behaviors. As we continue the research in the DRL literature, we must be mindful of which variation we are using as full-session was shown to nearly eliminate the target behavior that is being focused on, whereas spaced-responding was shown to reduce the behavior but not eliminate it. Future research must continue to evaluate its effectiveness on a variety of target behaviors. For example, researchers should evaluate the DRL variants with more RRBs as they are a concern for many families as discussed in our methods.

\section{Functional Analysis}

In this review only three studies used a functional analysis as part of their intervention. In recent years, the field of behavior analysis has moved towards using function-based treatments to reduce challenging behaviors, and function based treatments are considered among the most effective behavioral interventions (Iwata et al., 1982/1994). DRLs are not designed to require knowledge of function to work. They do, however, include components that might benefit from a knowledge of behavioral functions. For example, DRA uses an extinction component of not providing 
DIFFERENTIAL REINFORCEMENT OF LOW RATES

reinforcement to the target behavior. Given the positive improvements in reducing behavior with the DRL variation that targeted function-based behaviors (attention maintained, automatic), further examination of this topic is warranted (Bonner \& Borrero, 2017; Looney et al., 2018; Shaw \& Simms, 2009). A study might compare the treatment of attention-maintained behavior self-injurious behavior, and automatic self-injurious behaviors with these DRL variants.

\section{Experimental Design}

A majority of the collected studies used the reversal design to show experimental control. The reversal design should continue to be used in future research, as it has been the most potent within-subject design for demonstrating a functional relation between a DRL variation and behavior. This design should continue to be used moving forward as it has been used in over half of the DRL variants. The reversal design also allows for the most convincing demonstration of experimental control with the DRL variants.

\section{Number of sessions}

We calculated a range of 20 sessions up to 171 for the current DRL literature review. We believe there is nothing indicative to highlight he number of sessions used in the DRL variants.

\section{Setting}

Deitz (1977) noted that one benefit of using the DRL variations was that they are probably easier to implement for teachers. This seems to be supported by the literature, where the full-session DRL considered the easiest, was used in more than half of the studies. The full-session DRL has been discussed as the easiest DRL session to conduct, however there has never been a questionnaire provided to teachers or implementers to 
assess the feasibility of conducting this variant. Future research should consider social validity data from most implementers such as practitioners, teachers, and parents and provide them a questionnaire one which one is the least effortful. Over half of the articles reviewed were in classroom settings. These findings highlight a need for more research on the varied DRL variations in several different contexts. Given the number of studies that conducted a DRL procedure in the classroom setting. It would be beneficial to conduct DRL variations outside of the classroom and determine the efficacy as a standalone intervention. Other common settings where DRL might be useful include playground, therapy room, and at home. Studies in each of those environments would be useful to demonstrate that DRL can be useful in a variety of settings.

Future research should explore if there is a functional difference between the fullsession DRL, and interval DRL. However, if there is no functional difference, the data may suggest no real reason to separate the two terms. For example, researchers should evaluate under what functions of behavior does a full-session interval yield a greater reduction in behaviors, relative to the interval DRL variant.

\section{Limitations}

Despite this review's limitation of terminology, and that DRL procedures have yielded near zero rates for targeted behavior, several implications and future recommendations have been made when considering a DRL variation as a treatment for the future topic of study. These variations included spaced-responding, full-session, and interval. 


\section{Summary}

In summary, we reviewed 21 studies that included all three DRL variants including full-session, spaced-responding, and interval. We discovered that these variants are utilized in a range from a controlled therapy room to an open playground. These variants yielded results that were effective in reducing a variety of topographies of targeted behaviors. Limitations in the literature include the interchangeability that has been used with full-session, and interval DRL. Another limitation to this research is that the DRL procedures have been used to reduce target behaviors to near zero rates.

Although DRL's have been effective at reducing challenging behaviors, the use of DRLs in applied settings has been limited to a select few settings such as classrooms, and therapy rooms. We also know little about the percentage of improvement with each DRL variant. This procedure merits further investigation to understand when and how researchers are using DRL variations in applied settings. Previous DRL research studies aimed at a reduction in the focused targeted behavior of students with and out ASD. Considered the characteristics of these individuals, and educational settings. The outcomes have generally been favorable and have suggested effective DRL procedures. This review suggests that the DRL variations utilized have effectively decreased challenging behaviors across a variety of topographies. Also, the studies reviewed here point to the feasibility of conducting these DRL variations across various contexts. 
DIFFERENTIAL REINFORCEMENT OF LOW RATES

\section{Figures}

Table 1

Summary of DRL Variables

\begin{tabular}{|c|c|c|c|c|c|c|c|c|c|}
\hline $\begin{array}{l}\text { Studies in Alphabetical } \\
\text { Order }\end{array}$ & $\begin{array}{l}\text { Children } \\
\text { treated }\end{array}$ & Participants & DRL Variation & $\begin{array}{l}\text { Target } \\
\text { Behaviors }\end{array}$ & $\begin{array}{l}\text { Functional } \\
\text { Analysis }\end{array}$ & Design & $\begin{array}{l}\text { Number of } \\
\text { Sessions }\end{array}$ & Setting & $\begin{array}{l}\text { Percentage of } \\
\text { Improvement } \\
\text { (Decrease/Increase) }\end{array}$ \\
\hline Anglesea et al., 2008 & Autism & 3 & $\begin{array}{l}\text { Spaced- } \\
\text { Responding }\end{array}$ & Rapid Eating & No & Reversal & 28 & Classroom & $\begin{array}{l}\text { Spaced-Responding } \\
58 \%\end{array}$ \\
\hline Austin \& Bevan, 2011 & Autism & 3 & Full-Session & $\begin{array}{l}\text { Bids for } \\
\text { Attention }\end{array}$ & No & $\begin{array}{l}\text { Reversal } \\
\text { Design }\end{array}$ & 171 & Classroom & Full Session: $96 \%$ \\
\hline Becraft et al., 2018 & No Autism & 5 & $\begin{array}{l}\text { Spaced- } \\
\text { Responding } \\
\text { Full-Session }\end{array}$ & $\begin{array}{l}\text { Computer } \\
\text { Program }\end{array}$ & No & Reversal & $30-51$ & Classroom & N/A \\
\hline Becraft et al., 2017 & No Autism & 3 & $\begin{array}{l}\text { Spaced- } \\
\text { Responding } \\
\text { Full-Session }\end{array}$ & Excessive Bids & No & $\begin{array}{l}\text { Multi- } \\
\text { Element }\end{array}$ & $46-61$ & Classroom & $\begin{array}{l}\text { Spaced Responding: } \\
66 \% \\
\text { Full-Session: } 61 \%\end{array}$ \\
\hline Bonner \& Borrero, 2017 & Autism & 4 & Full-Session & $\begin{array}{l}\text { Self-Injurious } \\
\text { Behavior }\end{array}$ & Yes & Reversal & $20-25$ & $\begin{array}{l}\text { Therapy } \\
\text { Room }\end{array}$ & Full-Session: $97 \%$ \\
\hline Dietz \& Repp, 1973 & $\begin{array}{l}\text { Intellectual } \\
\text { Disability }\end{array}$ & 1 & Full-Session & Talk-Outs & No & Reversal & 35 & Classroom & Full Session: $98 \%$ \\
\hline Deitz \& Repp, 1974 & No Autism & 1 & Interval & Out-of-seat & No & Reversal & N/A & Classroom & Interval: $96 \%$ \\
\hline Deitz 1978 & $\begin{array}{l}\text { Intellectual } \\
\text { Disability }\end{array}$ & 1 & Interval & $\begin{array}{l}\text { Talking } \\
\text { inappropriately }\end{array}$ & No & Reversal & 35 & Classroom & Interval: $89 \%$ \\
\hline Gadaire et al., 2017 & $\begin{array}{l}\text { Intellectual } \\
\text { Disability }\end{array}$ & 5 & Full-Session & $\begin{array}{l}\text { Prosocial } \\
\text { Behaviors }\end{array}$ & No & Reversal & 30 & Playground & N/A \\
\hline Handen et al., 1984 & $\begin{array}{l}\text { Intellectual } \\
\text { Disability }\end{array}$ & 1 & Full-Session & $\begin{array}{l}\text { Repetitive } \\
\text { Speech }\end{array}$ & No & $\begin{array}{l}\text { Changing- } \\
\text { Criterion }\end{array}$ & 160 days & $\begin{array}{l}\text { Therapy } \\
\text { Room }\end{array}$ & Full-Session $94 \%$ \\
\hline Jessel \& Borrero, 2014 & No Autism & 16 & $\begin{array}{l}\text { Spaced- } \\
\text { Responding } \\
\text { Full-Session }\end{array}$ & $\begin{array}{l}\text { Computer } \\
\text { Program }\end{array}$ & No & Reversal & 15 & Classroom & $\begin{array}{l}\text { Spaced Responding: } \\
36 \% \\
\text { Full-Session: } 63 \%\end{array}$ \\
\hline Kostinas et al., 2001 & $\begin{array}{l}\text { Intellectual } \\
\text { Disability }\end{array}$ & 1 & Full-Session & $\begin{array}{l}\text { Perseverative } \\
\text { Verbalizations }\end{array}$ & No & Reversal & 140 & $\begin{array}{l}\text { Therapy } \\
\text { Room }\end{array}$ & Full-Session: $100 \%$ \\
\hline
\end{tabular}

Table 1 (Continued)

Summary of DRL Variables

\begin{tabular}{|c|c|c|c|c|c|c|c|c|c|}
\hline Laprime \& Dittrich, 2014 & Autism & 1 & Full-Session: & $\begin{array}{l}\text { Vocal } \\
\text { Stereotypy }\end{array}$ & Yes & $\begin{array}{l}\text { Changing- } \\
\text { Criterion }\end{array}$ & 171 & Classroom & Full-Session: $83 \%$ \\
\hline Lennox et al., 1987 & $\begin{array}{l}\text { Intellectual } \\
\text { Disability }\end{array}$ & 3 & $\begin{array}{l}\text { Spaced- } \\
\text { Responding }\end{array}$ & Rapid Eating & No & Reversal & 115 & $\begin{array}{l}\text { Therapy } \\
\text { Room }\end{array}$ & $\begin{array}{l}\text { Spaced Responding: } \\
50 \%\end{array}$ \\
\hline Looney et al., 2018 & Autism & 1 & Interval & $\begin{array}{l}\text { Repetitive } \\
\text { Behaviors }\end{array}$ & Yes & Reversal & 47 & $\begin{array}{l}\text { Therapy } \\
\text { Room }\end{array}$ & Interval: $92 \%$ \\
\hline Otalvaro et al., 2019 & $\begin{array}{l}\text { Intellectual } \\
\text { Disability }\end{array}$ & 2 & Full-Session & $\begin{array}{l}\text { Question } \\
\text { Asking }\end{array}$ & No & Reversal & 24 & $\begin{array}{l}\text { Therapy } \\
\text { Room }\end{array}$ & Full-Session: $77 \%$ \\
\hline Piper et al., 2019 & Autism & 4 & $\begin{array}{l}\text { Spaced- } \\
\text { Responding } \\
\text { Full-Session }\end{array}$ & $\begin{array}{l}\text { Computer } \\
\text { Program }\end{array}$ & No & Reversal & 36 & Classroom & $\begin{array}{l}\text { Spaced-Responding: } \\
73 \% \\
\text { Full-Session: } 49 \%\end{array}$ \\
\hline Shaw \& Simms, 2009 & $\begin{array}{l}\text { Intellectual } \\
\text { Disability }\end{array}$ & 3 & Full-Session & $\begin{array}{l}\text { Attention- } \\
\text { Maintained } \\
\text { behaviors }\end{array}$ & Yes & $\begin{array}{l}\text { Changing- } \\
\text { Criterion }\end{array}$ & 63 & Classroom & Full-Session:86\% \\
\hline Singh et al., 1981 & $\begin{array}{l}\text { Intellectual } \\
\text { Disability }\end{array}$ & 3 & $\begin{array}{l}\text { Spaced } \\
\text { Responding }\end{array}$ & $\begin{array}{l}\text { Motor } \\
\text { Stereotypy }\end{array}$ & No & Reversal & 40 & $\begin{array}{l}\text { Therapy } \\
\text { Room }\end{array}$ & $\begin{array}{l}\text { Spaced-Responding: } \\
86 \%\end{array}$ \\
\hline Turner et al., 1990 & No Autism & 1 & Full-Session & $\begin{array}{l}\text { Verbal } \\
\text { Aggression }\end{array}$ & No & $\begin{array}{l}\text { Multiple- } \\
\text { Baseline }\end{array}$ & 12 Weeks & $\begin{array}{l}\text { Therapy } \\
\text { Room }\end{array}$ & N/A \\
\hline Wright \& Vollmer, 2002 & $\begin{array}{l}\text { Intellectual } \\
\text { Disability }\end{array}$ & 1 & $\begin{array}{l}\text { Spaced- } \\
\text { Responding }\end{array}$ & Rapid Eating & No & Reversal & 45 & $\begin{array}{l}\text { Therapy } \\
\text { Room }\end{array}$ & $\begin{array}{l}\text { Spaced-Responding } \\
72 \%\end{array}$ \\
\hline
\end{tabular}


DIFFERENTIAL REINFORCEMENT OF LOW RATES

\section{References}

Allen, L., Gottselig, M., \& Boylan, S. (1982). A practical mechanism for using free time as a reinforcer in classrooms. Education and Treatment of Children,5(4), 347-353. http://www.jstor.org/stable/42898722

Alderman, N., \& Knight, C. (1997). The effectiveness of DRL in the management and treatment of severe behaviour disorders following brain injury. Brain Injury, 11(2), 79-102. https://doi.org/10.1080/026990597123683

American Psychiatric Association. (2013). Diagnostic and Statistical Manual of Mental Disorders. https://doi.org/10.1176/appi.books.9780890425596

Anglesea, M. M., Hoch, H., \& Taylor, B. A. (2008). Reducing rapid eating in teenagers with autism: use of a pager prompt. Journal of Applied Behavior Analysis, 41(1), 107-111. https://doi.org/10.1901/jaba.2008.41-107

Austin, J. L., \& Bevan, D. (2011). Using differential reinforcement of low rates to reduce children's requests for teacher attention. Journal of Applied Behavior Analysis, 44(3), 451-461. https://doi.org/10.1901/jaba.2011.44-451

Becraft, J. L., Borrero, J. C., Davis, B. J., Mendres-Smith, A. E., \& Castillo, M. I. (2018). The role of signals in two variations of differential-reinforcement-of-low-rate procedures. Journal of Applied Behavior Analysis, 51(1), 3-24. https://doi.org/10.1002/jaba.431

Becraft, J. L., Borrero, J. C., Mendres-Smith, A. E., \& Castillo, M. I. (2017). Decreasing excessive bids for attention in a simulated early education classroom. Journal of Behavioral Education, 26(4), 371-393. https://doi.org/10.1007/s10864-017-92756 


\section{DIFFERENTIAL REINFORCEMENT OF LOW RATES}

Bonner, A. C., \& Borrero, J. C. (2017). Differential reinforcement of low rate schedules reduce severe problem behavior. Behavior Modification, 42(5), 747-764. https://doi.org/10.1177/0145445517731723

Cooper, J. O., Heron, T. E., \& Heward, W. L. (2020). Applied behavior analysis. Pearson.

Cunningham, A. B., \& Schreibman, L. (2008). Stereotypy in autism: The importance of function. Research in Autism Spectrum Disorders, 2(3), 469-479. https://doi.org/10.1016/j.rasd.2007.09.006

Deitz, S. M. (1977). An analysis of programming DRL schedules in educational settings. Behaviour Research and Therapy, 15(1), 103-111. https://doi.org/10.1016/00057967(77)90093-6

Deitz, S. M., \& Repp, A. C. (1974). Differentially reinforcing low rates of misbehavior with normal elementary school children1. Journal of Applied Behavior Analysis, 7(4), 622-622. https://doi.org/10.1901/jaba.1974.7-622

Deitz, S. M., Slack, D. J., Schwarzmueller, E. B., Wilander, A. P., Weatherly, T. J., \& Hilliard, G. (1978). Reducing inappropriate behavior in special classrooms by reinforcing average interresponse times: Interval DRL. Behavior Therapy, 9(1), 37-46. https://doi.org/10.1016/s0005-7894(78)80052-5

Dietz, S. M., \& Repp, A. C. (1973). Decreasing classroom misbehavior through the use of DRL schedules of reinforcement1. Journal of Applied Behavior Analysis, 6(3), 457-463. https://doi.org/10.1901/jaba.1973.6-457

Ferster, C. B., \& Skinner, B. F. (1957). Schedules of Reinforcement. New York, NY Appleton-Century-Crofts. - References - Scientific Research Publishing. (n.d.). 


\section{DIFFERENTIAL REINFORCEMENT OF LOW RATES}

Flückiger, C., Wampold, B. E., Delgadillo, J., Rubel, J., Vîslă, A., \& Lutz, W. (2020). Is there an evidence-based number of sessions in outpatient psychotherapy? - a comparison of naturalistic conditions across countries. Psychotherapy and Psychosomatics, 89(5), 333-335. https://doi.org/10.1159/000507793

Gadaire, D. M., Marshall, G., \& Brissett, E. (2017). Differential reinforcement of low rate responding in social skills training. Learning and Motivation, 60, 34-40. https://doi.org/10.1016/j.lmot.2017.08.005

Handen, B. L., Apolito, P. M., \& Seltzer, G. B. (1984). Use of differential reinforcement of low rates of behavior to decrease repetitive speech in an autistic adolescent. Journal of Behavior Therapy and Experimental Psychiatry, 15(4), 359-364. https://doi.org/10.1016/0005-7916(84)90102-2

Iwata, B. A., Dorsey, M. F., Slifer, K. J., Bauman, K. E., \& Richman, G. S. (1982). Toward a functional analysis of self-injury. Analysis and Intervention in Developmental Disabilities, 2(1), 3-20. https://doi.org/10.1016/02704684(82)90003-9

Iwata, B. A., Dorsey, M. F., Slifer, K. J., Bauman, K. E., \& Richman, G. S. (1994). Toward a functional analysis of self-injury. Journal of Applied Behavior Analysis, 27(2), 197-209. https://doi.org/10.1901/jaba.1994.27-197

Jessel, J., \& Borrero, J. C. (2014). A laboratory comparison of two variations of differential-reinforcement-of-low-rate procedures. Journal of Applied Behavior Analysis, 47(2), 314-324. https://doi.org/10.1002/jaba.114

Kazdin, A. E. (2021). Single-case research designs: methods for clinical and applied settings. Oxford University Press. 


\section{DIFFERENTIAL REINFORCEMENT OF LOW RATES}

Koegel, R. L., \& Covert, A. (1972). The relationship of self-stimulation to learning in autistic children1. Journal of Applied Behavior Analysis, 5(4), 381-387. https://doi.org/10.1901/jaba.1972.5-381

Kostinas, G., Scandlen, A., \& Luiselli, J. K. (2001). Effects of DRL and DRL combined with response cost on perseverative verbal behavior of an adult with mental retardation and obsessive compulsive disorder. Behavioral Interventions, 16(1), 27-37. https://doi.org/10.1002/bin.70

Laprime, A. P., \& Dittrich, G. A. (2014). An evaluation of a treatment package consisting of discrimination training and differential reinforcement with response cost and a social story on vocal stereotypy for a preschooler with autism in a preschool classroom. Education and Treatment of Children, 37(3), 407-430. https://doi.org/10.1353/etc.2014.0028

LeGray, M. W., Dufrene, B. A., Mercer, S., Olmi, D. J., \& Sterling, H. (2013). Differential reinforcement of alternative behavior in center-based classrooms: evaluation of pre-teaching the alternative behavior. Journal of Behavioral Education, 22(2), 85-102. https://doi.org/10.1007/s10864-013-9170-8

Lennox, D. B., Miltenberger, R. G., \& Donnelly, D. R. (1987). Response interruption and drl for the reduction of rapid eating. Journal of Applied Behavior Analysis, 20(3), 279-284. https://doi.org/10.1901/jaba.1987.20-279

Leon, Y., Lazarchick, W. N., Rooker, G. W., \& DeLeon, I. G. (2013). Assessment of problem behavior evoked by disruption of ritualistic toy arrangements in a child with autism. Journal of Applied Behavior Analysis, 46(2), 507-511. https://doi.org/10.1002/jaba.41 


\section{DIFFERENTIAL REINFORCEMENT OF LOW RATES}

Looney, K., DeQuinzio, J. A., \& Taylor, B. A. (2018). Using self-monitoring and differential reinforcement of low rates of behavior to decrease repetitive behaviors: A case study. Behavioral Interventions, 33(3), 251-259. https://doi.org/10.1002/bin.1517

Lovaas, O. I., Litrownik, A., \& Mann, R. (1971). Response latencies to auditory stimuli in autistic children engaged in self-stimulatory behavior. Behaviour Research and Therapy, 9(1), 39-49. https://doi.org/10.1016/0005-7967(71)90035-0

Otalvaro, P. A., Krebs, C. A., Brewer, A. T., Leon, Y., \& Steifman, J. S. (2019). Reducing excessive questions in adults at adult-day training centers using differential-reinforcement-of-low rates. Journal of Applied Behavior Analysis. https://doi.org/10.1002/jaba.603

Piper, A., Borrero, J. C., \& Becraft, J. L. (2019). Differential reinforcement-of-low-rate procedures: A systematic replication with students with autism spectrum disorder. Journal of Applied Behavior Analysis. https://doi.org/10.1002/jaba.631

Poling, A., \& Ryan, C. (1982). Differential- Reinforcement-of-Other-Behavior Schedules. Behavior Modification, 6(1), 3-21. https://doi.org/10.1177/01454455820061001

Roane, H. S., Fisher, W. W., Sgro, G. M., Falcomata, T. S., \& Pabico, R. R. (2004). An alternative method of thinning reinforcer delivery during differential reinforcement. Journal of Applied Behavior Analysis, 37(2), 213-218. https://doi.org/10.1901/jaba.2004.37-213 


\section{DIFFERENTIAL REINFORCEMENT OF LOW RATES}

Schlinger, H. D., Blakely, E., Fillhard, J., \& Poling, A. (1991). Defining terms in behavior analysis: Reinforcer and discriminative stimulus. The Analysis of Verbal Behavior, 9(1), 153-161. https://doi.org/10.1007/bf03392869

Shaw, R., \& Simms, T. (2009). Reducing attention-maintained behavior through the use of positive punishment, differential reinforcement of low rates, and response marking. Behavioral Interventions, 24(4), 249-263.

https://doi.org/10.1002/bin.287

Singh, N. N., Dawson, M. J., \& Manning, P. (1981). Effects of spaced responding DRL on the stereotyped behavior of profoundly retarded persons. Journal of Applied Behavior Analysis, 14(4), 521-526. https://doi.org/10.1901/jaba.1981.14-521

Turner, J. M., Green, G., \& Braunling-McMorrow, D. (1990). Differential reinforcement of low rates of responding (drl) to reduce dysfunctional social behaviors of a head injured man. Behavioral Interventions, 5(1), 15-27.

https://doi.org/10.1002/bin.2360050103

Turner, M. (1999). Annotation: Repetitive Behaviour in Autism: A Review of Psychological Research. Journal of Child Psychology and Psychiatry, 40(6), 839849. https://doi.org/10.1111/1469-7610.00502

Vollmer, T. R., Roane, H. S., Ringdahl, J. E., \& Marcus, B. A. (1999). Evaluating treatment challenges with differential reinforcement of alternative behavior. Journal of Applied Behavior Analysis, 32(1), 9-23. https://doi.org/10.1901/jaba.1999.32-9 


\section{DIFFERENTIAL REINFORCEMENT OF LOW RATES}

Wong, C., Odom, S. L., Hume, K. A., Cox, A. W., Fettig, A., Kucharczyk, S., Schultz, T. R. (2015). evidence-based practices for children, youth, and young adults with autism spectrum disorder: a comprehensive review. Journal of Autism and Developmental Disorders, 45(7), 1951-1966. https://doi.org/10.1007/s10803-0142351-z

Wright, C. S., \& Vollmer, T. R. (2002). Evaluation of a treatment package to reduce rapid eating. Journal of Applied Behavior Analysis, 35(1), 89-93. https://doi.org/10.1901/jaba.2002.35-89

Zimmerman, J., \& Schuster, C. R. (1962). Spaced responding in multiple drl schedules. Journal of the Experimental Analysis of Behavior, 5(4), 497-504. https://doi.org/10.1901/jeab.1962.5-497 


\section{Appendix: A Code Sheet}

\begin{tabular}{|c|c|}
\hline \multicolumn{2}{|c|}{ Code Information } \\
\hline Name: & \\
\hline Date: & \\
\hline
\end{tabular}

\section{Search Procedure}

Academic Database:

Search Term

\section{Citation}

\section{Report Characteristics}

\begin{tabular}{|c|l|}
\hline Authors: & \\
\hline Year: & \\
\hline Title & \\
\hline Journal: & \\
\hline
\end{tabular}

\begin{tabular}{|c|c|c|c|}
\hline \multicolumn{5}{|c|}{ Participants Characteristics } \\
\hline Age & Setting & Diagnosis & Notes \\
\hline & & & \\
\hline & & & \\
\hline & & & \\
\hline & & & \\
\hline
\end{tabular}

*For diagnosis choose from the three:

Intellectual Disability: Any diagnosis that includes mental retardation, developmental disability, or any neurodevelopmental disability that isn't labeled Autism Spectrum Disorder.

Autism Spectrum Disorder: Any diagnosis that is labeled autistic, or includes the terms Autism Spectrum Disorder

Typically Developing: Does not include any diagnosis of any neurodevelopmental disability, autism spectrum disorder, or any definitions that would meet the other two diagnosis. 
DIFFERENTIAL REINFORCEMENT OF LOW RATES

\section{Appendix: B Database Search Sheet}

\begin{tabular}{|c|c|c|c|}
\hline \multicolumn{4}{|c|}{ Database Search } \\
\hline Database Used: & Keywords & $\begin{array}{l}\text { Number } \\
\text { of Hits }\end{array}$ & Citations \\
\hline \multirow{4}{*}{ EBSCOhost } & $\begin{array}{l}\text { Differential Reinforcement of } \\
\text { Low Rates \& Autis* }\end{array}$ & & \\
\hline & $\begin{array}{l}\text { Differential Reinforcement of } \\
\text { Low Rates and Intellectual } \\
\text { Disabilities }\end{array}$ & & \\
\hline & Interresponse Time and Autis* & & \\
\hline & Interresponse Time and & & \\
\hline \multirow{4}{*}{ PsychINFO } & $\begin{array}{l}\text { Differential Reinforcement of } \\
\text { Low Rates \& Autis* }\end{array}$ & & \\
\hline & $\begin{array}{l}\text { Differential Reinforcement of } \\
\text { Low Rates and Intellectual } \\
\text { Disabilities }\end{array}$ & & \\
\hline & Interresponse Time and Autis* & & \\
\hline & Interresponse Time and & & \\
\hline \multirow{4}{*}{ PubMed } & $\begin{array}{l}\text { Differential Reinforcement of } \\
\text { Low Rates \& Autis* }\end{array}$ & & \\
\hline & $\begin{array}{l}\text { Differential Reinforcement of } \\
\text { Low Rates and Intellectual } \\
\text { Disabilities }\end{array}$ & & \\
\hline & Interresponse Time and Autis* & & \\
\hline & Interresponse Time and & & \\
\hline \multirow{4}{*}{ SpringerLink } & $\begin{array}{l}\text { Differential Reinforcement of } \\
\text { Low Rates \& Autis* }\end{array}$ & & \\
\hline & $\begin{array}{l}\text { Differential Reinforcement of } \\
\text { Low Rates and Intellectual } \\
\text { Disabilities }\end{array}$ & & \\
\hline & Interresponse Time and Autis* & & \\
\hline & Interresponse Time and & & \\
\hline
\end{tabular}

\begin{tabular}{|c|cc|}
\hline \multicolumn{2}{|c|}{ Eligibility Check } \\
\hline Single Subject Design: & Yes & No \\
\hline Peer-Reviewed & Yes & No \\
\hline Published in English: & Yes & No \\
\hline $\begin{array}{c}\text { Learner with or without ASD or intellectual } \\
\text { disability }\end{array}$ & Yes & No \\
\hline $\begin{array}{c}\text { Minimum of 16 Sessions Using DRL } \\
\text { Used a DRL Variation (Spaced-Responding, } \\
\text { Full-Session, Interval) }\end{array}$ & Yes & No \\
\hline Functional Analysis & Yes & No \\
\hline
\end{tabular}

